\title{
Expression of the Type III Secretion System Genes in Epiphytic Erwinia amylovora Cells on Apple Stigmas Benefits Endophytic Infection at the Hypanthium
}

\author{
Zhouqi Cui, ${ }^{1}$ Regan B. Huntley, ${ }^{1}$ Neil P Schultes, ${ }^{1}$ Kaleem U. Kakar, ${ }^{2}$ Ching-Hong Yang, ${ }^{3}$ and Quan Zeng ${ }^{1, \dagger}$ \\ ${ }^{1}$ Department of Plant Pathology and Ecology, The Connecticut Agricultural Experiment Station, New Haven, CT 06504, \\ U.S.A. \\ ${ }^{2}$ Department of Microbiology, Faculty of Life Sciences and Informatics, Balochistan University of Information Technology, \\ Engineering and Management Sciences (BUITEMS), Quetta, 87300, Pakistan \\ ${ }^{3}$ Department of Biological Sciences, University of Wisconsin-Milwaukee, Milwaukee, WI 53211, U.S.A.
}

Accepted 15 July 2021.

Erwinia amylovora causes fire blight on rosaceous plants. One of the major entry points of $E$. amylovora into hosts is flowers, where $E$. amylovora proliferates epiphytically on stigmatic and hypanthium surfaces and, subsequently, causes endophytic infection at the hypanthium. The type III secretion system (T3SS) is an important virulence factor in $E$. amylovora. Although the role of T3SS during endophytic infection is well characterized, its expression during epiphytic colonization and role in the subsequent infection is less understood. Here, we investigated T3SS gene expression in epiphytic E. amylovora on stigma and hypanthium of apple flowers under different relative humidities (RH). On stigma surfaces, T3SS was expressed in a high percentage of $E$. amylovora cells, and its expression promoted epiphytic growth. On hypanthium surfaces, however, T3SS was expressed in fewer $E$. amylovora cells than on the stigma, and displayed no correlation with epiphytic growth, even though T3SS expression is essential for infection. $E$. amylovora cells grown on stigmatic surfaces and then flushed down to the hypanthium displayed a higher level of T3SS expression than cells grown on the hypanthium surface alone. Furthermore, $E$. amylovora cells precultured on stigma had a higher potential to infect flowers than $E$. amylovora cells precultured in a T3SSrepressive medium. This suggests that T3SS induction during the stigmatic epiphytic colonization may be beneficial for subsequent infection. Finally, epiphytic expression of T3SS was influenced by RH. Higher percentage of stigmatic $E$. amylovora cells expressed T3SS under high RH than under low RH.

${ }^{\dagger}$ Corresponding author: Q. Zeng; Quan.Zeng@ct.gov

Funding: Support was provided by a Northeastern IPM Center partnership grant, the United States Department of Agriculture (USDA) National Institute of Food and Agriculture (NIFA) Agricultural Microbiome 202067013-31794, USDA-NIFA Organic Transitions 2017-51106-27001, and USDA-Specialty Crop Block Grant through the State of Connecticut Department of Agriculture.

*The $\boldsymbol{e}$-Xtra logo stands for "electronic extra" and indicates that supplementary figures and a supplementary table are published online.

The author(s) declare no conflict of interest.

(c) (1) $(\Theta)$ Copyright $(92021$ The Author(s). This is an open access article distributed under the CC BY-NC-ND 4.0 International license.
Keywords: epiphytic colonization, Erwinia amylovora, fire blight, T3SS

Erwinia amylovora is a Gram-negative phytopathogenic bacterium that causes fire blight disease on apple, pear, and other rosaceous plants. E. amylovora can infect various parts of hosts, including flowers, fruitlets, shoots, and rootstocks. Among them, infection on flowers, referred to as blossom blight, is of the most importance in disease epidemiology and management (Bubán and Orosz-Kovács 2003). Flowers provide a nutrientrich and moist environment suitable for epiphytic growth of E. amylovora (Norelli and Brandl 2004). Flowers also contain natural openings that serve as entry points of E. amylovora into the hypanthium interior that normally develops into the apple fruit pulp. Infected flowers quickly wilt and are unable to produce fruit, resulting in yield losses. Moreover, after the initial infection of flowers, pathogens can quickly move down branches and limbs and to other parts of the tree. Annual losses to fire blight and cost of control are estimated over \$100 million in the United States alone (Norelli et al. 2003).

E. amylovora utilizes several virulence factors to successfully cause disease (Kharadi et al. in press). Arguably the most essential virulence factor is the type III secretion system (T3SS). T3SS is a needle-like structure that translocates effector proteins from the pathogen cells into host cells (Notti and Stebbins 2016). The T3 effectors suppress host immunity and induce plant cell death (Boureau et al. 2006). In E. amylovora, the T3SS includes the secretion apparatus, effectors, and other translocated proteins that are encoded by three clusters of $34 \mathrm{hrp}$, $h r c$, and $d s p$ genes (Sebaihia et al. 2010; Yuan et al. 2020). Because of its importance in pathogenicity, regulation of T3SS in E. amylovora has been intensively studied. Many different types of regulators such as $\sigma$ factors (Ancona et al. 2014), twocomponent signal transduction systems ( $\mathrm{Li}$ et al. 2014), protease (Lee et al. 2018), regulatory small RNAs (Schachterle et al. 2019; Zeng and Sundin 2014; Zeng et al. 2013), as well as bacterial secondary messengers (Ancona et al. 2015; Edmunds et al. 2013; Kharadi and Sundin 2020) have been identified to control the expression of T3SS genes. The evidence from these studies, albeit indirect, is that the fire blight pathogen E. amylovora senses environmental signals and adjusts T3SS gene expression accordingly.

Bacterial pathogen modulation of virulence gene expression in response to host and environmental signals has been documented 
(Cui et al. 2015; Pusey 2000). Although virulence factors such as T3SS are nonessential to cellular metabolism and growth, their synthesis and assembly are costly in terms of energy and material and can impose a penalty on bacterial growth (Cui et al. 2019). For this reason, pathogens tend to express virulence genes only when necessary. For instance, in necrotrophic plant pathogen Dickeya dadantii, T3SS is highly expressed at the early stage of infection but is subsequently diminished at a later stage of infection (Cui et al. 2018). In E. amylovora, expression of key T3S genes ( $h r p, d s p A$, and $d s p E$ ) were activated in a narrow time window, peaking between 24 and $48 \mathrm{~h}$ postinoculation on flowers (Pester et al. 2012) and 3 and $6 \mathrm{~h}$ in hrp-inducing minimal medium (Wei et al. 1992). Most work investigating virulence gene expression focused on the endophytic stages of infection, when pathogens are present in the intercellular space of the plant and directly associated with symptom development.

Although the endophytic stage of infection has drawn most research attention, pathogen proliferation and migration epiphytically on plant surfaces is also an indispensable phase of infection, as observed in Pseudomonas syringae ( $\mathrm{Yu}$ et al. 2013), Xanthomonas axonopodis (Gent et al. 2005), and Pantoea ananatis (Coutinho and Venter 2009). Prior to causing infection at the floral cup, E. amylovora first colonizes the stigma surfaces and multiplies epiphytically using nutrients present in stigma exudates (Pusey 1997; Pusey et al. 2008). With the aid of freemoving water such as dew and rain, the stigmatic population of E. amylovora migrates down to the hypanthium, and initiates the endophytic stage of infection through natural openings called nectarthodes (Bubán and Orosz-Kovács 2003; Thomson 1986). The epiphytic growth of E. amylovora is heavily influenced by many environmental factors such as temperature, relative humidity (RH), and precipitation (Pusey 2000; Pusey and Curry 2004). However, it is unclear how expression of virulence genes such as T3SS during the epiphytic stage of infection would benefit endophytic infection at the hypanthium.

In this study, we hypothesized that the fire blight pathogen E. amylovora grown epiphytically on flowers expresses T3SS genes in response to spatial, temporal, and environmental signals. We also hypothesize that the variations in T3SS expression is not random but, instead, confers biological significance in promoting pathogen colonization and infection. We monitored the T3SS gene expression levels at stigma and hypanthium of apple flowers under different RH $(60,80$, and $100 \%)$ over a period of 3 days. Epiphytic pathogen population size and infection rate of the ovary tissue were also determined in tandem with the T3SS gene expression to establish any correlation and thereby link T3SS function. Our findings suggest that epiphytic colonization of E. amylovora on flowers not only builds up a sizable pathogen population but also induces pathogen virulence, both of which are important for the successful infection at the hypanthium.

\section{RESULTS}

\section{E. amylovora expresses T3SS genes in a proportion of the total cells.}

To monitor the expression of T3SS genes in planta, we constructed a dual-fluorescence reporter plasmid, pPhrpA-PnptII, which contains an $n p t I I$ promoter-green fluorescent protein $(g f p)$ transcriptional fusion and an $h r p A$ promoter- $m$ Cherry transcriptional fusion on one plasmid. This construct enables all E. amylovora cells to be green fluorescent, whereas only cells that expressed $h r p A$, a gene encoding the T3 pilus, were red fluorescent. We observed that, among all E. amylovora cells under the same in planta conditions (shoots, fruitlets, and flowers), only a subpopulation highly expressed $h r p A$ while the rest of the cells did not express hrpA (Supplementary Fig. S1A). The hrpA-expressing cells ranged from 35 to $70 \%$ in different conditions tested (Table 1), with its expression on stigma being the highest and in shoots the lowest. As a negative control, a non-T3SS gene, gapA, which encodes a glyceraldehyde-3-phosphate dehydrogenase, was evenly expressed in all cells (Supplementary Fig. S1B).

To determine whether cells that highly expressed $h r p A$ also highly expressed other T3SS genes, we constructed two other dual reporters, pPhrpA-PdspE and pPhrpA-PhrpJ, and observed the coexpression of $h r p A$ with $d s p E$ (encoding a T3 effector) or hrpJ (encoding a T3-secreted protein). When cultured in the in vitro $h r p$-inducing medium, cells highly expressing $h r p A$ also simultaneously highly expressed $d s p E$ or hrpJ (Supplementary Fig. S2). Taken together, these observations suggest that expression of T3SS genes occurs in an organized, tandem manner to allow the functional establishment of T3SS in a subpopulation of E. amylovora cells. By adjusting the percentage of geneexpressing cells ("on" cells) in a population, E. amylovora adjusted the overall expression level of T3SS, similar to what was reported in other pathogen systems (Cui et al. 2018). Hereafter, we used the percentage of the hrpA-expressing cells to represent the percentage of T3SS-expressing cells and the overall T3SS expression in a population.

\section{On stigma, T3SS expression promotes epiphytic} growth of $E$. amylovora and is positively affected by RH.

On stigma surfaces, percentage of $h r p A$-expressing E. amylovora cells increased as colonization progressed (Fig. 1A). By day 3,70\% of total cells expressed hrpA (Fig. 1A). We observed that, as the RH rose, the percentage of E. amylovora cells in a population that expressed $h r p A$ also increased (Fig. 1A and D), suggesting that RH positively affects the expression of T3SS in E. amylovora during its colonization on stigma. Interestingly, RH also had an impact on the growth of E. amylovora. Higher RH resulted in a higher epiphytic population of E. amylovora on stigma than those grown at a lower RH (Fig. 1B). A positive correlation between T3SS expression and bacterial growth was observed $\left(R^{2}=0.98\right)$ (Fig. 1C). These observations support the idea that the presence of T3SS benefits epiphytic growth of E. amylovora on stigmas.

To test this hypothesis, we compared the epiphytic growth of wild-type E. amylovora, a T3SS mutant ( $\Delta$ hrpL), and an E. amylovora strain overexpressing hrpL (nptII-hrpL) on the stigma surface. A clear growth retardation was observed when T3SS was inactivated $(\Delta h r p L) 2$ and 3 days postinoculation at both 80 and $100 \%$ RH compared with wild type and nptII-hrpL $(P<0.05)$ (Fig. 2A). Overexpression of $h r p L$ resulted in slightly faster growth than the wide type at 2 and 3 days postinoculation, although the difference was not statistically significant $(P<0.05)$ (Fig. 2A). These data, together with the observation that epiphytic

Table 1. Percentage of $h r p A$-expressing $\left(h r p A^{\mathrm{ON}}\right.$ ) cells in total Erwinia amylovora population under in planta colonization

\begin{tabular}{lc}
\hline Location, time (h) & $\boldsymbol{h r p \boldsymbol { A } ^ { \mathbf { O N } } \text { cells } ( \% )}$ \\
\hline Shoots & \\
24 & $45.0 \pm 12.5$ \\
48 & $44.4 \pm 13.6$ \\
72 & $37.4 \pm 8.9$ \\
Fruitlets & \\
24 & $57.8 \pm 4.0$ \\
48 & $45.3 \pm 7.9$ \\
72 & $53.1 \pm 10.7$ \\
Flowers (stigma surfaces) & \\
24 & $52.8 \pm 9.4$ \\
48 & $68.9 \pm 14.5$ \\
72 & $68.7 \pm 9.4$ \\
\hline
\end{tabular}


growth of E. amylovora and its T3SS expression are positively correlated, suggests that the expression of T3SS supports epiphytic growth of E. amylovora on stigmatic surfaces.

\section{$d s p E$ is translocated into host cells on stigma.}

To determine whether expression of T3SS genes in stigmagrown E. amylovora cells leads to the translocation of T3 effectors into host cells, we used a previously established translocation assay with T3-secreted effector DspE fused with an adenylate cyclase (CyaA) gene (Triplett et al. 2009). Elevated cyclic AMP levels were detected in stigmas inoculated with E. amylovora carrying the $\mathrm{DspE}_{(1-737)}-\mathrm{CyaA}$ reporter, compared with stigmas from noninoculated flowers or inoculated with $E$. amylovora carrying a DspE with a truncated translocation signal (DspE $\left.\mathrm{B}_{(1-15)}-\mathrm{CyaA}\right)$ (Fig. 3). This confirmed that T3SS is not only actively expressed on stigma but also actively functions as a protein translocation mechanism delivering effector proteins into host cells.

\section{Compared with stigma, T3SS expression in $E$. amylovora} is much lower on the hypanthium surface, and is not related to epiphytic growth.

Compared with on stigma surfaces, expression of T3SS in epiphytic E. amylovora cells is much lower on the hypanthium surfaces (Fig. 4; Supplementary Fig. S3). On day 1, almost no cells expressed $h r p A$ on hypanthium surfaces. The percentage of $h r p A$-expressing cells barely reached $25 \%$ by day 3 . The fact that T3SS expression is very low, especially at the initial stage of colonization, suggests that T3SS may not be as beneficial for the epiphytic growth of E. amylovora on the hypanthium surface as it is on the stigma. To test this hypothesis, we compared the epiphytic growth rate of the wild-type E. amylovora with growth rate of the $\Delta h r p L$ on the hypanthium surface. We did not observe any growth retardation in $\Delta h r p L$ in comparison with the wild type $(P>0.05)$ (Fig. 2B), which confirmed that T3SS expression is not as beneficial for E. amylovora to colonize the hypanthium surface as it is on the stigma.

The hypanthium surface is not only nutrient rich and able to support epiphytic growth of microbes but also contains natural openings (nectarthodes) where pathogens enter into the hypanthium and cause infection. To determine whether T3SS is needed for E. amylovora to cause infection in the hypanthium, next, we inoculated the wild type and $\Delta h r p L E$. amylovora on the hypanthium surface and evaluated the blossom blight symptoms at a later time (after 3 to 4 days). Interestingly, even though $\Delta h r p L$ grew as well as the wild type on the hypanthium, flowers inoculated with $\Delta h r p L$ remained healthy whereas $92 \%$ of flowers inoculated with the wild type developed water
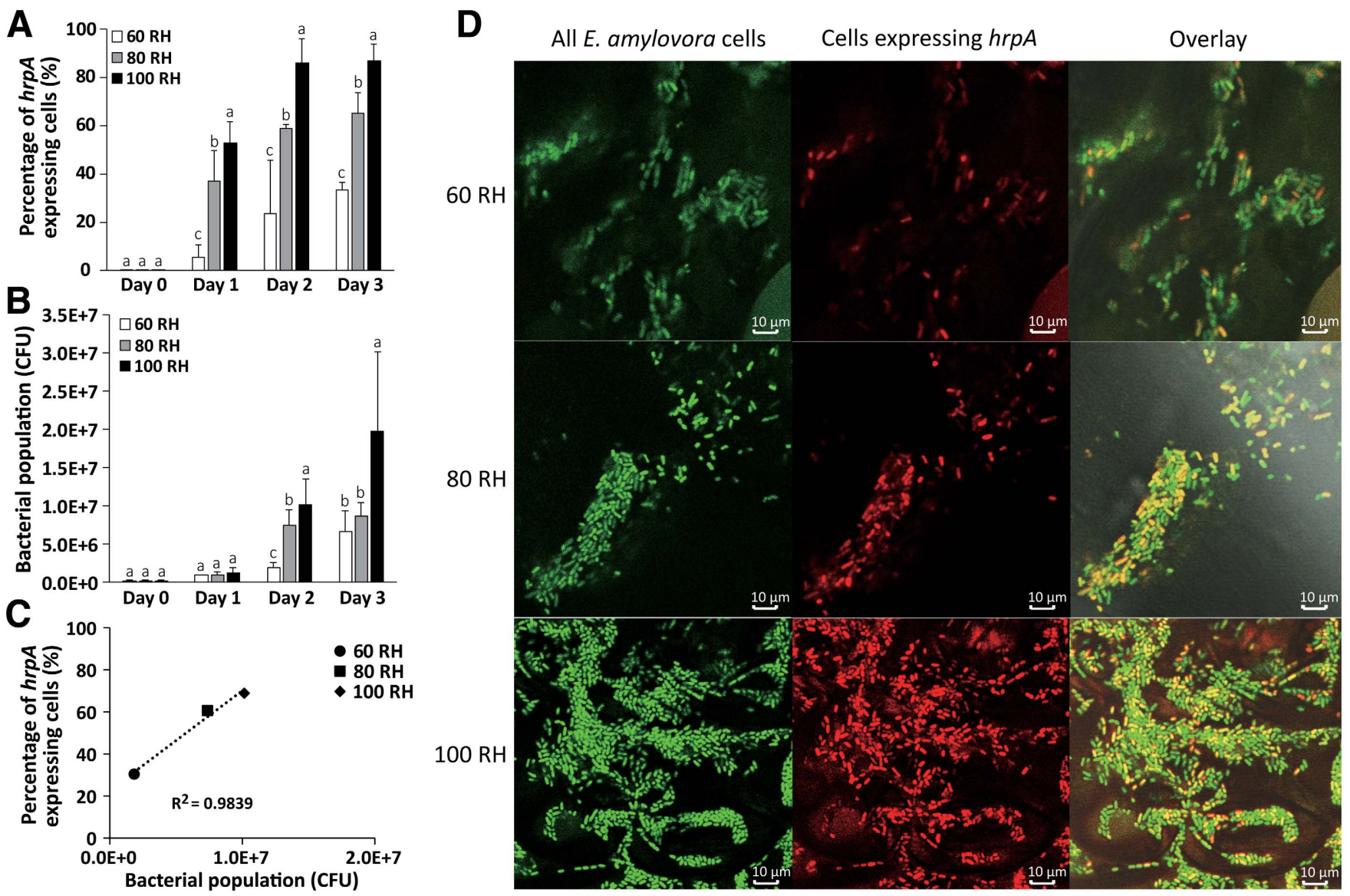

Fig. 1. Expression of hrpA in epiphytic Erwinia amylovora cells on apple stigma surfaces and its correlation with bacterial growth under various relative humidities (RH). A, Percentage of hrpA-expressing cells ( $r r p A^{\mathrm{ON}}$ cells) in the total E. amylovora cells on stigma surfaces when flowers were maintained under different RH $(60,80$, and $100 \%)$ within the first 3 days after inoculation. E. amylovora carrying the dual reporter pPhrpA-PnptII was inoculated onto the stigma portion of detached apple flowers. The percentage was obtained from the number of green and red fluorescent bacterial cells observed with a fluorescence microscope. At least five images were taken at each time point. Different letters denote statistical significance $(P<0.05$, identified by analysis of variance). B, E. amylovora cell counts on stigmas under 60, 80, and 100\% RH within the first 3 days postinoculation. Flowers used for cell count determination were maintained under the same experimental setting as the flowers used for the hrpA expression monitoring. Cell counts were determined by plating on lysogeny broth agar plates. C, Correlation between the percentage of $h r p A^{\mathrm{ON}}$ cells and the bacterial population under 60,80 , and $100 \% \mathrm{RH}$ at $48 \mathrm{~h}$ postinoculation. D, Visualization of $h r p A^{\mathrm{ON}}$ cells in total E. amylovora cells on stigma under 60,80 , and $100 \% \mathrm{RH} 2$ days postinoculation using a confocal microscope. All E. amylovora cells were visualized by green fluorescence and the $h r p A^{\mathrm{ON}}$ cells were visualized by red fluorescence. 
soaking and blight symptoms 3 and 4 days, respectively, after inoculation (Fig. 5).

If T3SS expression is, indeed, needed for infection in the hypanthium, we would expect that the level of T3SS expression would be higher in endophytic E. amylovora cells present internally in the infected hypanthium tissue, even though T3SS expression levels are low for hypanthium surface-grown cells. Indeed, a much higher level of hrpA expression was observed in the internal tissue of the hypanthium (approximately 60\%) (Fig. 6) than on the hypanthium surface $(<25 \%)$. Taken together, our data suggest that T3SS expression is not needed for the epiphytic growth of E. amylovora at the hypanthium surface but is required for the subsequent endophytic infection inside the hypanthium.

Epiphytic growth of $E$. amylovora on the stigma primes its virulence prior to hypanthium infection.

The stigma surface is a T3SS-inducing environment, whereas the hypanthium surface is a T3SS-noninducing environment (Fig. 4). We hypothesize that, during natural infection, colonization of E. amylovora on the stigma surface may not only help to establish a large pathogen population but also to prime the pathogen's virulence, which increases the likelihood of infection at the hypanthium. To test this hypothesis, we measured the hrpA expression in E. amylovora cells directly inoculated on the hypanthium and in cells that first grew on the stigma and were then flushed down to the hypanthium. hrpA expression was significantly higher in cells flushed from the stigma down to the hypanthium (Fig. 4, red line) than in cells that had been grown on the hypanthium surface from the beginning (Fig. 4, blue line). This suggests that stigma colonization does, indeed, prime E. amylovora virulence prior to reaching to the hypanthium.

E. amylovora cells epiphytically grown on the stigma have a better chance to infect the hypanthium interior than $E$. amylovora cells grown

in an hrp-repressing, nutrient-rich medium.

To determine whether virulence-primed E. amylovora cells grown on stigma would have a better chance to infect than cells without such virulence induction, we prepared two different inoculums. The first inoculum consisted of virulence-primed E. amylovora cells collected from E. amylovora-inoculated stigmas and the second inoculum consisted of virulence-suppressed E. amylovora cells grown overnight in nutrient-rich broth (lysogeny broth [LB]) (Supplementary Fig. S4). The two inoculums were serial diluted and inoculated onto the hypanthium surface to allow blossom blight symptom development. Flowers that received the same inoculum source but with increasing pathogen numbers resulted in higher infection rates, suggesting that pathogen population size is positively correlated to the infection rate
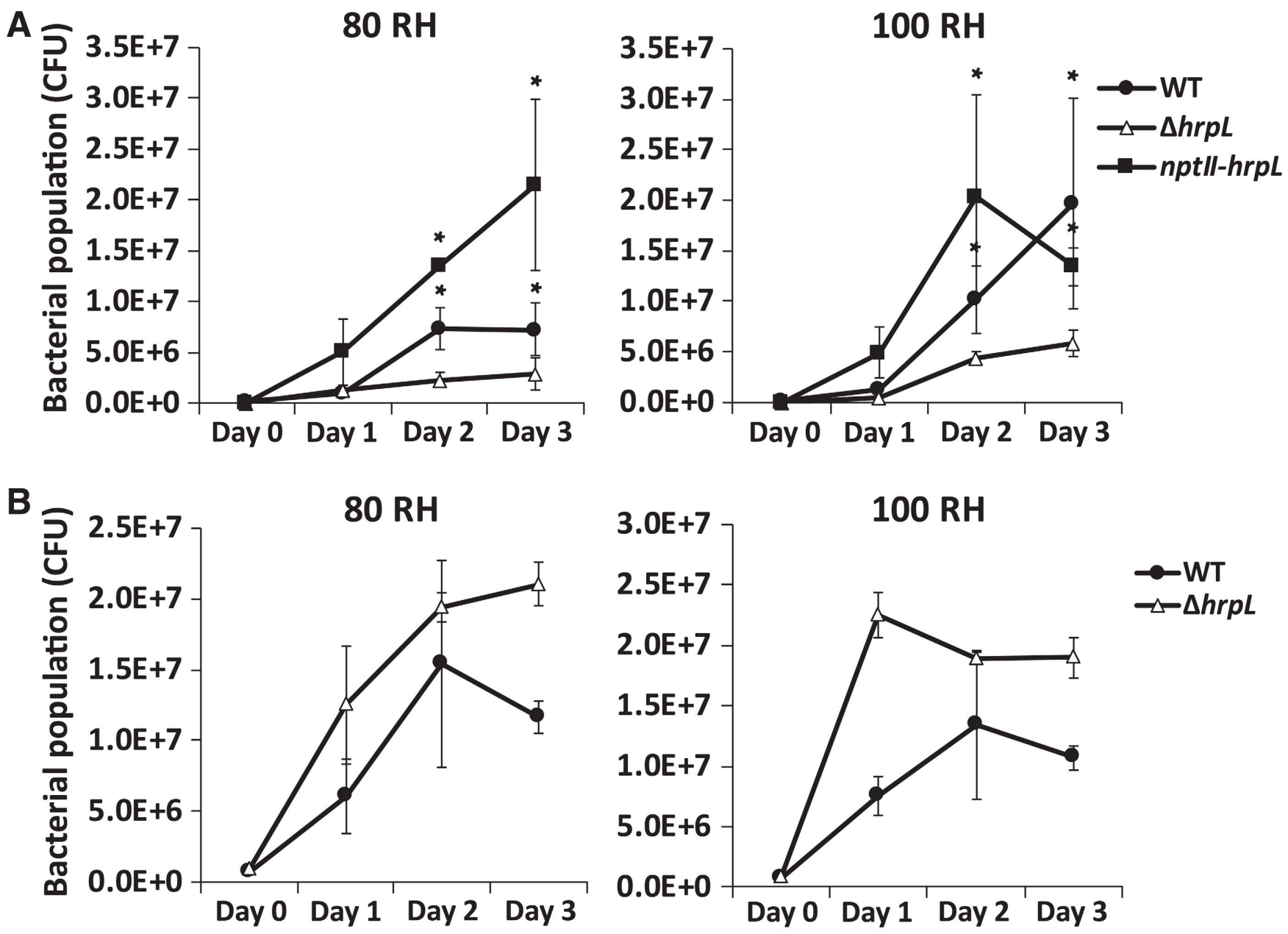

Fig. 2. Growth of Erwinia amylovora on A, stigma and B, hypanthium surfaces in the presence and absence of type III secretion system. E. amylovora wild type (WT) and $h r p L$ deletion mutant $(\Delta h r p L)$ were inoculated onto stigma (A) and hypanthium (B) surfaces of detached apple flowers. Inoculated flowers were maintained under 80 and $100 \%$ relative humidity (RH). Cell counts were determined by plating on day 0 to day 3 . E. amylovora carrying an overexpression construct of $h r p L$ (nptII- $h r p L)$ was also tested on stigma. Data points and error bars represent the means and standard deviations of three biological replicates. Asterisks denote statistical significance in comparison with $\Delta h r p L(P<0.05)$. 
(Fig. 7). This was observed with both inoculum types. However, when we compared the infection rate of the two different inoculum sources, we observed that stigma-reared E. amylovora were more efficient at infection (infection/inoculum cell number) than cells cultured in LB medium. Stigma-grown cells infected flowers at an inoculum concentration 10 to 100 times lower than cells grown in LB (Fig. 7). For example, in the 2020 experiment, $1.4 \times 10^{5}$ E. amylovora cells harvested from an LB culture were needed to cause approximately $30 \%$ of infection on the inoculated flowers, whereas only $2.4 \times 10^{3} \mathrm{E}$. amylovora cells harvested from stigma were needed to reach a similar level of infection rate (Fig. 7). This suggests that enhanced T3SS gene expression in stigma-grown epiphytic cells benefits infection later at the hypanthium.

\section{DISCUSSION}

Prior to this study, research determined the major steps in establishing floral fire blight infections. It was understood that E. amylovora initially colonizes and propagates mainly on apple stigma, establishing a large epiphytic population (Johnson et al. 2009; Spinelli et al. 2005; Thomson 1986; Wilson et al. 1989). With the help of free-moving water such as rain or dew, the pathogen cells migrate from stigma down to the hypanthium and enter the host through nectarthodes (Pusey 2000). It is also known that the T3SS is a key virulence factor in E. amylovora (Oh et al. 2005), and expression of $d s p E$ was observed on stigma (Johnson et al. 2009). Johnson et al. (2009) also showed that $h r p L$ was also shown to promote epiphytic growth on stigma. However, there is a lack of systemic study to understand the expression of T3SS genes in epiphytic E. amylovora present on different flower parts and its biological functions in regards to blossom blight infection. Our study demonstrated that T3SS translocation of effector protein DspE occurred during the epiphytic colonization and pathogenesis of E. amylovora on the

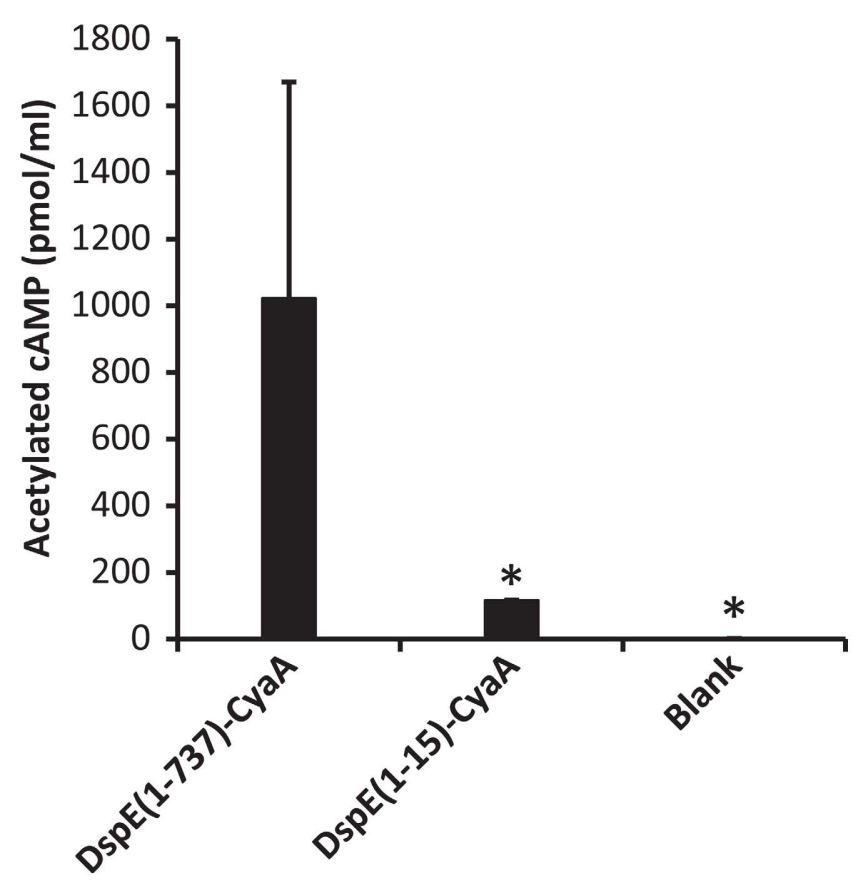

Fig. 3. Translocation of type III effector DspE into stigma cells. cAMP accumulation was determined in apple stigmas inoculated with Erwinia amylovora 1189 expressing $\mathrm{DspE}_{(1-737)}-\mathrm{CyaA}$ and $\mathrm{DspE}_{(1-15)}-\mathrm{CyaA}$. Each sample contained stigmas of eight flowers. Uninoculated flowers were used as blank control. Data points and error bars represent the means and standard deviations of three biological replicates. Stars denote statistical significance $(P<0.05$, identified by analysis of variance). stigma. The expression of T3SS not only benefits growth of E. amylovora on the stigma surface (Fig. 2), as observed by Johnson et al. (2009), but also primed virulence (enhancing T3SS expression), thereby increasing the infectivity of $E$. amylovora once it gained entry to the hypanthium interior. Stigmagrown E. amylovora cells with T3SS expression induced would have enough T3SS structures present for infection, even though they would encounter the T3SS-noninducing conditions at the hypanthium surface. A summary of the expression dynamics and biological functions of T3SS during the blossom blight infection is illustrated in Figure 8.

Predominantly, pathogen virulence gene expression such as T3SS has been viewed and investigated during the endophytic phase of infection (Pfeilmeier et al. 2016). Here, we showed that expression of T3SS genes may benefit the epiphytic growth of E. amylovora during the epiphytic colonization of flowers in a tissue-dependent manner. T3SS expression is beneficial for the epiphytic growth on stigma, as observed by Johnson et al. (2009), although not required for the growth of E. amylovora at the hypanthium surface, where these genes are induced at lower levels. Growth of E. amylovora at the hypanthium surface is generally less vigorous than on the stigma surface (approximately two orders of magnitude lower than on stigmas), possibly due to low osmotic potential. Through the CyaA translocation assay, we demonstrated that T3 effector DspE was, indeed, translocated into host cells on stigmatic surfaces. DspE, a member of the AvrE superfamily effector, is known to induce host cell death. The induction of host cell death by DspE can likely result in leakage of host nutrients on this secretory organ (stigma), thus supporting the pathogen's growth. This observation, in agreement with a recent report showing that T3SS is beneficial for the epiphytic growth of Pseudomonas syringae on bean and tomato leaves (Stauber et al. 2012; Wilson et al. 1999), suggests that pathogens utilizing plant nutrients on plant surfaces could be a proactive rather than passive process. The proactive nutrient acquisition or fitness promotion was also observed in E. herbicola, in which the production of indole-3-acetic acid promotes its epiphytic fitness on plants (Brandl and Lindow 1998).

T3SS genes could be induced by host signals when the pathogens are present in plant apoplast (Haapalainen et al. 2009; Yang et al. 2008). However, whether environmental signals such as RH would also affect the expression of T3SS is not well understood. Fire blight infections occur more often and are more severe under humid conditions or after rain compared with dry weather conditions. However, the correlation of the water to disease severity is often explained by the fact that E. amylovora

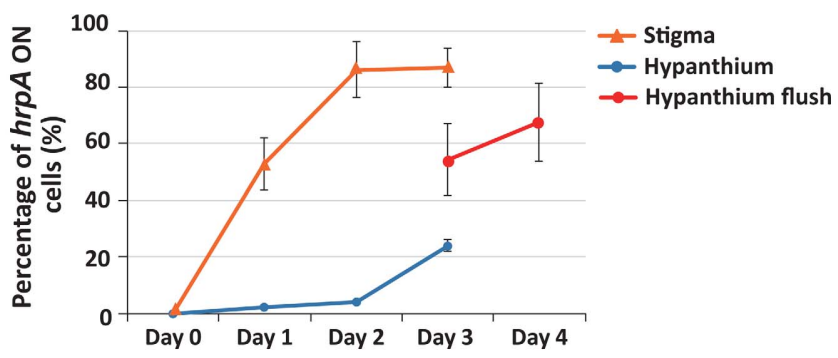

Fig. 4. Percentage of $h r p A$-expressing cells $\left(h r p A^{\mathrm{ON}}\right.$ cells) in the total population on stigma surfaces (orange line), hypanthium surfaces (blue line), and hypanthium surfaces with inoculum acquired from stigma surfaces through water flushing (red line). Erwinia amylovora carrying the pPhrpA-PnptII dual reporter was inoculated directly onto the stigma surface (orange line), hypanthium surface (blue line), and first on stigma surface and allowed to grow for 2 days and flushed down to the hypanthium with $5 \mu \mathrm{l}$ of water on day 2 (red line). Flower samples were maintained under $80 \%$ relative humidity and their green and red fluorescence was determined using a confocal microscope. Data points and error bars represent the means and standard deviations of three biological replicates. 
grows faster under the humid condition than under the dry condition, and by the dilution of nectar to increase the water potential, as shown by Pusey (2000). In this study, we further demonstrated that humid conditions not only favor the growth of E. amylovora but also induce more pathogen cells to express virulence genes (T3SS) than during dryer conditions. Because virulence gene expression is critical for infections, enhanced T3SS expression could lead to increased infection rates. This was proven in our inoculation assay using the T3SS-induced E. amylovora cells precultured on stigma and cells grown in a T3SS-repressive condition, showing that cells with T3SS gene expression induced can cause a similar level of disease with at least 10-fold less inoculum than cells that are not induced (Fig. 7). Previous studies have shown that bacterial pathogens

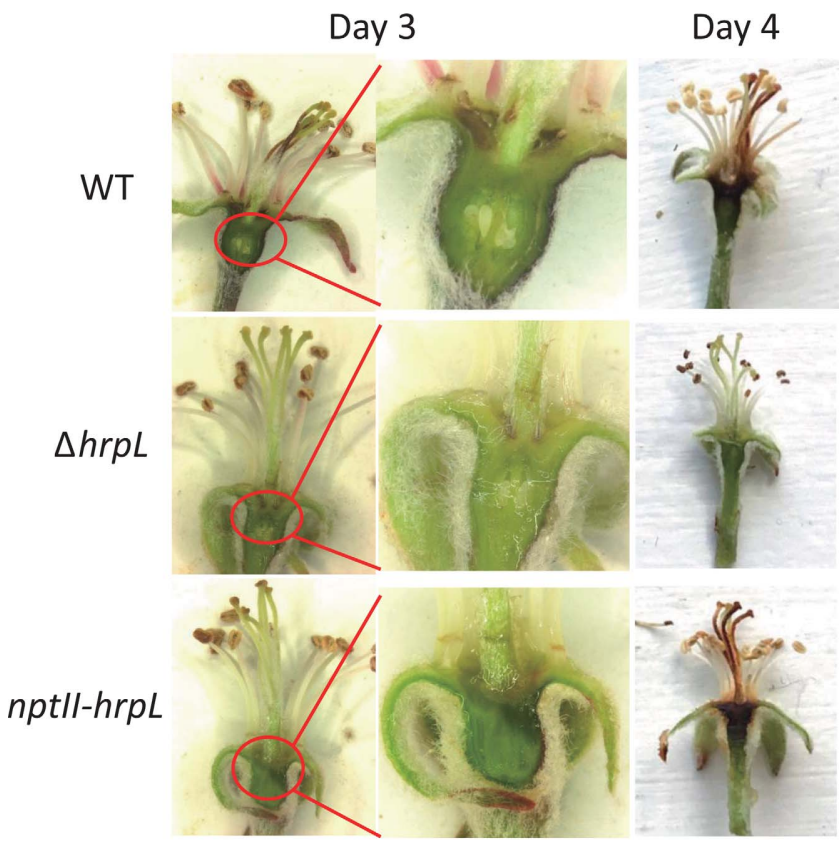

Fig. 5. Disease symptoms caused by Erwinia amylovora wild type (WT), hrpL deletion mutant $(\Delta h r p L)$, and E. amylovora with an overexpression construct of hrpL (nptII-hrpL) when inoculated on the hypanthium surface after 3 and 4 days. E. amylovora at a concentration of $10^{8}$ $\mathrm{CFU} / \mathrm{ml}$ was inoculated onto the hypanthium surfaces. Inoculated flowers were maintained at $28^{\circ} \mathrm{C}$ and at $100 \%$ relative humidity prior to disease symptom examination.

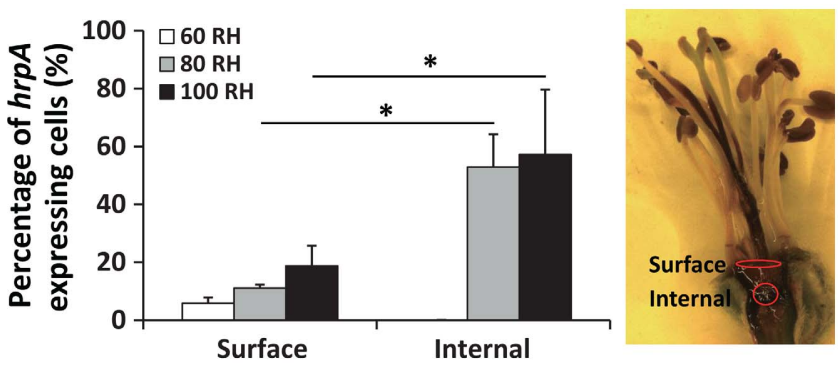

Fig. 6. Expression of hrpA in Erwinia amylovora grown epiphytically on hypanthium surfaces and endophytically in infected internal tissue of hypanthium at 60,80 , and $100 \%$ relative humidity (RH). E. amylovora carrying the pPhrpA-PnptII dual fluorescent reporter was inoculated on hypanthium surfaces and maintained at 60, 80, and $100 \%$ RH. Four days postinoculation, green and red fluorescence of samples collected from hypanthium surfaces and from the infected tissue located internally in the hypanthium was observed using a fluorescence microscope. Data points and error bars represent the means and standard deviations of three biological replicates. Stars denote statistical significance $(P<0.05$, identified by analysis of variance). are able to create an aqueous intercellular space in the apoplast endophytically, which benefits the subsequent infection (Xin et al. 2016). Findings from this study highlight the importance of water and $\mathrm{RH}$ during the epiphytic colonization and infection of plant-pathogenic bacteria.

We observed that, even though all E. amylovora cells are exposed to the same host environment, expression of T3SS genes is restricted to a subpopulation of all pathogen cells (a bistable expression). This phenomenon was observed in both epiphytic and endophytic stages of infection. This phenomenon was first reported by Johnson et al. (2009); however, the total E. amylovora cells were not labeled. Thus, it is unknown whether the GFP-negative cells were contamination of other nonE. amylovora bacteria, or E. amylovora that lost the fluorescent plasmid. The functionality and expression pattern of T3SS bistable expression was also uncharacterized. Here, using a dual-fluorescent reporter system, we clearly marked the total live E. amylovora population and distinguished the subpopulation that expressed T3SS, thus clearly illustrating the bistable nature of the T3SS expression. Furthermore, we showed that different $h r p$ and $d s p$ genes are simultaneously expressed in the on cells but not in the gene-nonexpressing (off) cells. Finally, the percentage of on cells varied in different host environments (e.g., shoots, flowers, and fruitlets). These observations support the hypothesis that E. amylovora expresses T3SS genes and establishes the complex protein secretion structure only in a subpopulation during infection of the host. The incentives of not having the T3SS "turned on" in all bacterial cells may be due to the fact that establishing this nonessential, complex protein secretion system is energy costly and may impose a growth penalty, as observed in other plant and animal pathogens (Cui et al. 2018, 2019; Johnson et al. 2009; Rufián et al. 2016; Sturm et al. 2011), or perhaps to avoid triggering host immunity.

\section{MATERIALS AND METHODS}

Bacterial strains, plasmids, and media.

Strains of E. amylovora and Escherichia coli were cultured in $\mathrm{LB}$ medium at 28 and $37^{\circ} \mathrm{C}$, respectively. All strains were stored at $-80^{\circ} \mathrm{C}$ in $15 \%$ glycerol. For in vitro induction of T3SS, an overnight culture of Erwinia amylovora was subcultured in a hrp-inducing minimal medium (Yang et al. 2007). When necessary, antibiotics were added to the medium at the following concentrations: chloramphenicol, $30 \mu \mathrm{g} / \mathrm{ml}$; kanamycin, $50 \mu \mathrm{g} / \mathrm{ml}$; ampicillin, $100 \mu \mathrm{g} / \mathrm{ml}$; and spectinomycin, $50 \mu \mathrm{g} / \mathrm{ml}$.

\section{Construction of dual-fluorescence reporter plasmids.}

Dual fluorescence reporter pPhrpA-PnptII plasmid was modified from a previously constructed plasmid pAT-PnptII-gfpPhrpA3937-mCherry (Cui et al. 2018). Briefly, the hrpA promoter was PCR amplified from the E. amylovora 1189 chromosome, digested as a SacI and BamHI fragment to replace the promoter $h r p A 3937$, resulting in the pAT-PhrpA $A_{E a}$-PnptII plasmid. Then, the whole fragment of PnptII-gfp-PhrpA $E a-m C h e r r y$ was PCR amplified using pAT-PhrpA $A_{E a}$-PnptII plasmid as the template, and was digested by KpnI and SalI. The released fragment was subsequently cloned into vector pCL1920 between the same restriction enzyme sites to obtain pPhrpA-PnptII. The pPgapA-PnptII, pPhrpA-PhrpJ, and pPhrpA-PdspE plasmids were subsequently constructed by replacing the $h r p A_{E a}$ promoter with the promoter of gapA, and by replacing the $n p t I I$ promoter with the promoter of $h r p J$ or $d s p E$, respectively. All constructs were confirmed by sequencing, and the primer sequences are listed in Supplementary Table S1.

Construction of $h r p L$ deletion and overexpression strains.

The $\Delta h r p L$ deletion mutant was constructed in a previous study (McNally et al. 2012). A chromosomal hrpL overexpression strain 
of $E$. amylovora was constructed using a previously reported $\lambda$ red recombinase method to replace the original promoter of $h r p L$ with an $n p t I I$ promoter (Datsenko and Wanner 2000; Zhao et al. 2009). Briefly, the nptII promoter was PCR amplified from plasmid pKD4 (Datsenko and Wanner 2000) using primers containing 50-nucleotide homology arms of $h r p L$ promoter regions flanking constitutively expressed promoter $n p t I I$. The kanamycin resistance cassette gene kan was also amplified from plasmid pKD4. The amplified PCR fragments of PnptII and kan were digested by EcoRI/BamHI and KpnI/EcoRI, respectively. The digested fragments were cloned into vector pBSK+ (Stratagene, La Jolla, CA, U.S.A.) to acquire pBSK-Km-PnptII. The PCR products of KmPnptII were amplified, purified, and electroporated into E. amylovora 1189 strain expressing the recombinase gene from the helper plasmid pKD46. The PnptII-hrpL strain was selected on LB medium amended with kanamycin and ampicillin and confirmed by PCR and sequencing.

\section{Detached apple flower assay.}

Apple flower clusters were collected from Macoun apple trees during bloom, placed on ice, and transferred to the laboratory for immediate processing. Freshly opened flowers with petals expanded $80 \%$ were detached from flower clusters, and placed in $10-\mathrm{ml}$ plastic tubes with the petiole submerged in $10 \%$ sucrose solution, as described by Pusey (2000). Tubes holding the flowers were placed on plastic tube racks enclosed in 4-liter plastic containers with 1 liter of glycerol-water mixture for the purpose of maintaining various levels of RH. The correlation curve linking glycerol concentration to $\mathrm{RH}$ was established in a previous study (Johnson 1940). The RH was maintained at $60 \%$ (62.7\% glycerol), $80 \%$ (37.5\% glycerol), and $100 \%$ (no glycerol). Each humidity chamber contained 40 to 50 flower samples.

To prepare inoculum, E. amylovora 1189 strains were grown overnight in LB medium (adjusting to an optical density at 600 $\mathrm{nm}=1.0)$. The overnight culture was collected by centrifugation at $9,000 \times g$ for $1 \mathrm{~min}$ and resuspended in $0.5 \times$ phosphatebuffered saline (PBS) for inoculation. For stigma inoculation,
$2 \mu \mathrm{l}$ of inoculum was evenly distributed among five stigmas on each flower using a micropipette. For hypanthium inoculation, $1 \mu \mathrm{l}$ of inoculum suspension was directly placed on the hypanthium surface on each flower. For water-flushed treatments, stigma was originally inoculated with E. amylovora as described above. At 2 days postinoculation, $5 \mu \mathrm{l}$ of sterile water was pipetted onto the stigmas of each flower with gentle mixing, followed by pipetting the water containing E. amylovora cells directly to the hypanthium surface. Flowers for the flushing assay were

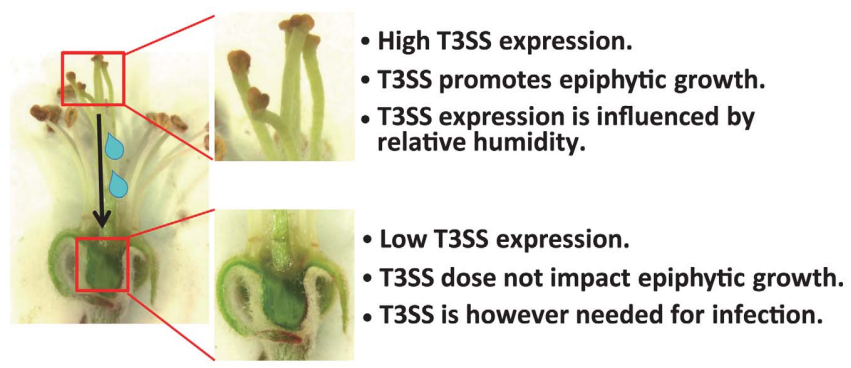

Fig. 8. Illustration of the expression dynamics of type III secretion system (T3SS) genes in Erwinia amylovora when colonizing stigma and hypanthium, and its role in epiphytic multiplication of the pathogen and infection. E. amylovora was spread to stigma and initially grew epiphytically on the stigma surface. On stigma, E. amylovora expresses high levels of T3SS genes. The translocation of the T3 effector DspE causes host cell death and helps the bacteria to obtain host resources and build up a large pathogen population. The T3SS expression of E. amylovora on stigma is highly influenced by relative humidity: more cells turned on T3SS under high humidity than at low humidity. A wetting event (rain or dew) moves pathogen cells from stigma down to the hypanthium. The hypanthium, possibly due to nectar's high sugar concentration and the lack of direct host cell contact blocked by the epidermis, represents a T3SS-repressive environment. Epiphytic growth of E. amylovora on hypanthium does not require a functional T3SS. However, T3SS function is needed for the successful infection of the internal tissue of hypanthium. The epiphytic growth of E. amylovora on stigma surfaces primes the pathogen's virulence, which helps to overcome the T3SS repressive condition at the hypanthium surfaces and increases its chance of successful invasion at the internal tissue of hypanthium.
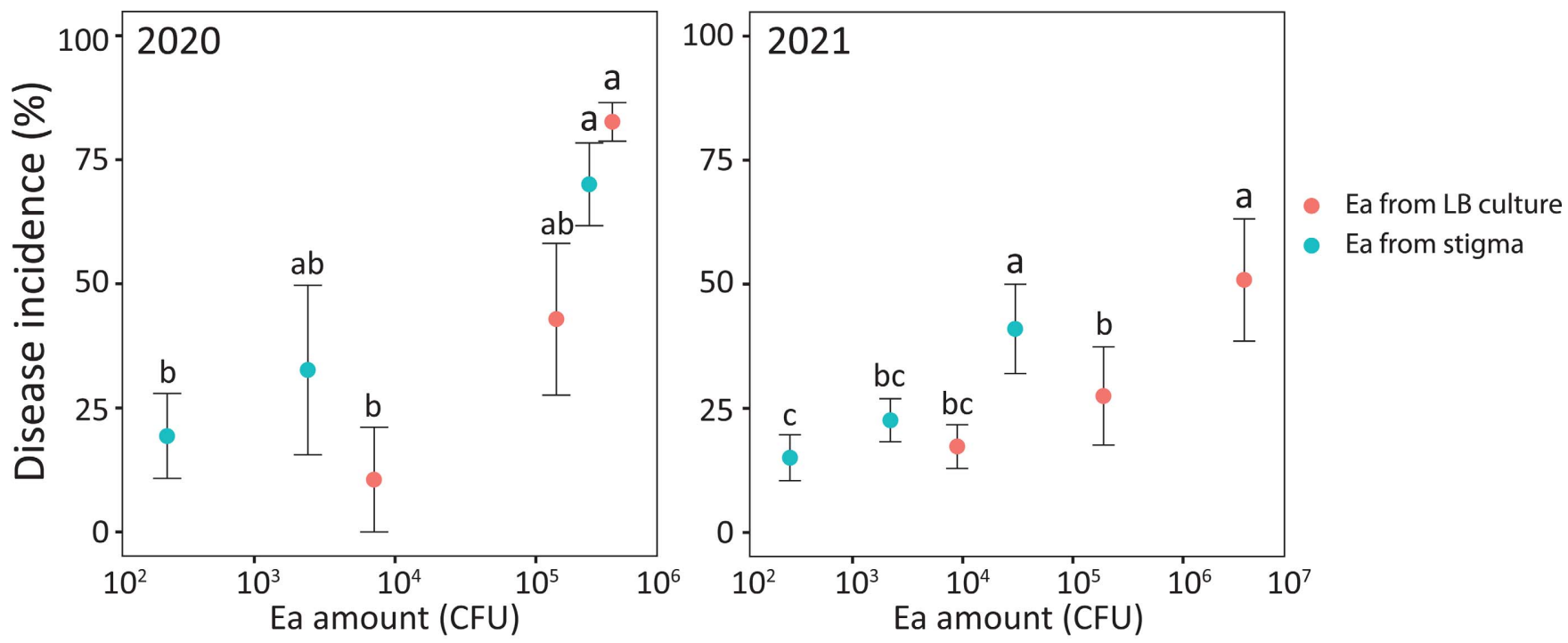

Fig. 7. Correlation between fire blight disease incidence and Erwinia amylovora (Ea) quantification in the inoculum when the inoculum was sourced from overnight lysogeny broth (LB) culture and from preinoculated stigma. Inoculum from stigma was prepared by first spray inoculating stigmas of freshly opened flowers with an E. amylovora suspension $\left(10^{7} \mathrm{CFU} / \mathrm{ml}\right)$. Stigma portions of the flowers were cut by scissors and collected into a 15 -ml centrifuge tube with $0.5 \times$ phosphate-buffered saline 2 days after inoculation. E. amylovora cells were washed from the stigma surfaces by vortexing and sonication. The LB inoculum was prepared by culturing E. amylovora in LB medium at $28^{\circ} \mathrm{C}$ overnight. Inoculums of the two sources were serial diluted. A proportion of the inoculum was pipetted to the hypanthium surface of individual flowers, and the rest of the inoculum was plated on LB plates for measuring bacterial cell counts. The experiment was performed on apple trees at Lockwood Farm, Hamden, Connecticut, in May 2020 and May 2021. Three replicates were included in each treatment, with at least 50 flowers in each replicate. Symptoms of individual flowers were determined 3 weeks after the original inoculation. Different letters denote statistical significance $(P<0.05$, identified by analysis of variance). 
maintained at $80 \% \mathrm{RH}$ prior to visualizing the expression of $h r p A$ at the hypanthium 24 and $48 \mathrm{~h}$ after the water flush. Each treatment had at least five replicates and the experiments were repeated three times.

\section{Shoot and fruitlet inoculation.}

For shoot inoculation, freshly grown succulent apple shoots (cultivar Gala) were inoculated with E. amylovora by cutting the tip of the youngest shoots with a scissors dipped in a suspension of E. amylovora 1189 at $10^{8} \mathrm{CFU} / \mathrm{ml}$. Inoculated shoots were bagged with plastic Ziploc bags to maintain high humidity conditions. For fruitlets inoculation, fruitlets (approximately $1.5 \mathrm{in.}$ in diameter) were sterilized with $10 \%$ bleach and wounded by a 0.2-mm syringe needle. An E. amylovora 1189 suspension $(5 \mu \mathrm{l})$ at $10^{7} \mathrm{CFU} / \mathrm{ml}$ was placed at each wound. The inoculated fruitlets were incubated at $28^{\circ} \mathrm{C}$ in an enclosed container with wet paper towels. The experiments were repeated three times.

\section{Confocal and epifluorescence microscopy.}

Fresh stigma, hypanthium, or other plant samples were dissected into $2-\mathrm{mm}^{2}$ sections, mounted on microscope slides, and covered by cover slips. The cover slip was secured to the slide with scotch tape. The green and red fluorescence was observed using either a Leica SP5 confocal microscope or a Zeiss Axioplan 2 fluorescence microscope. The Leica SP5 confocal microscope (Leica, Wetzlar, Germany) has four laser channels (405 nm, multiline Argon, $561 \mathrm{nM}$ and $633 \mathrm{~nm}$ ) and two HyD detectors. The Zeiss Axioplan 2 fluorescence microscope (Zeiss, Oberkochen, Germany) contains three fluorescence filter sets: 02 EX G365, 10 EX BP450-490, and 15 EX BP 546/12. Overlay of green and red fluorescence images was performed using Leica LAS-X software (Schneider et al. 2012). For each specimen at each time point, more than 10 random microscopic fields were captured and the average percentage of red and green fluorescent cells was calculated using numbers from all captured images.

\section{Quantification of epiphytic E. amylovora population.}

For stigma samples, five stigmas inoculated with E. amylovora $\mathrm{pPhrpA-PnptII}$ from each flower were dissected from the styles and placed in $1.5-\mathrm{ml}$ microcentrifuge tubes containing $200 \mu \mathrm{l}$ of $0.5 \times$ PBS. For hypanthium samples, the hypanthium tissue was obtained by removing the corolla, calyx, and pedicel. Both liquid present on the hypanthium surface (nectar) and the hypanthium tissue of each flower were collected as a single sample. Hypanthium samples were collected into sterile $1.5-\mathrm{ml}$ Eppendorf tubes with $200 \mu \mathrm{l}$ of $0.5 \times$ PBS. The tubes were then sonicated for $2 \mathrm{~min}$ in a water bath sonicator, followed by vortexing for $15 \mathrm{~s}$. The bacteria-containing PBS buffer was serially diluted and plated on LB agar plates supplemented with ampicillin for determination of cell counts. The experiments were repeated three times.

\section{The CyaA translocation assay.}

The E. amylovora full-length DspE-CyaA reporter (DspE 1-737CyaA) and the N-terminal DspE fragment-CyaA reporter (DspE $\left.\mathrm{D}_{1-15}-\mathrm{CyaA}\right)$ were constructed in a previous study (Triplett et al. 2009). Overnight cultures of the above strains were adjusted to $1 \times 10^{7} \mathrm{CFU} / \mathrm{ml}$ in $0.5 \times \mathrm{PBS}$ and were sprayed on flowers of apple cultivar Macoun at the same stage of bloom. At 2 days postinoculation, the stigma portion of each flower was dissected and collected into a 1.5-ml microcentrifuge tube. Stigmas of eight flowers were pooled together as one sample. Collected samples were kept on ice during transportation and were stored at $-80^{\circ} \mathrm{C}$ until cAMP determination. cAMP was extracted according to the method reported by Castiblanco et al. (2018). Briefly, frozen flower stigmas were ground and resuspended in
$250 \mu \mathrm{l}$ of $0.1 \mathrm{M} \mathrm{HCl}$. Suspensions were centrifuge at $3,000 \times g$ for $5 \mathrm{~min}$ and the cAMP levels in supernatants were measured using the cAMP EIA Kit (Cayman Chemical, Ann Arbor, MI, U.S.A.) according to the manufacturer's instructions. Statistical analyses were performed using a one-way analysis of variance least significant difference test. The experiment was repeated three times.

\section{Quantification of disease incidence using inoculum collected from stigma and from an overnight culture in a nutrient-rich medium.}

To prepare inoculum from stigma, overnight-cultured E. amylovora cells at a concentration of $10^{7} \mathrm{CFU} / \mathrm{ml}$ were spray inoculated to open flowers of apple trees (Malus $\times$ domestica 'McIntosh') maintained at Lockwood Farm of the Connecticut Agricultural Experiment Station. The stigma portions of approximately 300 inoculated flowers were harvested 2 days postinoculation and pooled together into a sterile $15-\mathrm{ml}$ centrifuge tube. Then, $10 \mathrm{ml}$ of $0.5 \times$ PBS were added into the tube containing the stigmas, which was sonicated for $5 \mathrm{~min}$ and vortexed for $30 \mathrm{~s}$. To prepare inoculum from a nutrient-rich, hrp-repressing condition, E. amylovora 110 was cultured in LB medium overnight at $28^{\circ} \mathrm{C}$. Cell counts of live E. amylovora from both stigma and LB culture were determined by serial dilution and plating on LB agar plates.

The inoculum from stigma and from LB overnight culture was serial diluted and inoculated onto hypanthium of freshly opened flowers on six McIntosh trees. in total, six inoculum treatments, including three serial-diluted stigma samples and three serialdiluted LB samples, were inoculated on 18 branches, with each treatment inoculated on 3 branches. Each branch contained more than 60 individual flowers at stage of bloom. Inoculum $(10 \mu \mathrm{l})$ was added to the hypanthium by hand with a pipette.

Three weeks after pathogen inoculation, inoculated flowers were rated for blossom blight symptoms (black withering, dying of the apple flowers, and emergence of ooze droplets). Percentage of diseased individual flowers in the total number of individual flowers was determined for each treatment. This experiment was repeated twice in May 2020 and May 2021 with similar observations.

\section{ACKNOWLEDGMENTS}

We thank J. La Reau, S. Diallo, R. Cecarelli, R. Hannan, and M. McHill for their excellent technical support.

\section{LITERATURE CITED}

Ancona, V., Lee, J. H., Chatnaparat, T., Oh, J., Hong, J.-I., and Zhao, Y. 2015. The bacterial alarmone (p)ppGpp activates type III secretion system in Erwinia amylovora. J. Bacteriol. 197:1433-1443.

Ancona, V., Li, W., and Zhao, Y. 2014. Alternative sigma factor RpoN and its modulation protein $\mathrm{YhbH}$ are indispensable for Erwinia amylovora virulence. Mol. Plant Pathol. 15:58-66.

Boureau, T., ElMaarouf-Bouteau, H., Garnier, A., Brisset, M.-N., Perino, C., Pucheu, I., and Barny, M.-A. 2006. DspA/E, a type III effector essential for Erwinia amylovora pathogenicity and growth in planta, induces cell death in host apple and nonhost tobacco plants. Mol. Plant-Microbe Interact. 19:16-24.

Brandl, M. T., and Lindow, S. E. 1998. Contribution of indole-3-acetic acid production to the epiphytic fitness of Erwinia herbicola. Appl. Environ. Microbiol. 64:3256-3263.

Bubán, T., and Orosz-Kovács, Z. 2003. The nectary as the primary site of infection by Erwinia amylovora (Burr.) Winslow et al.: A mini review. Plant Syst. Evol. 238:183-194.

Castiblanco, L. F., Triplett, L. R., and Sundin, G. W. 2018. Regulation of effector delivery by type III secretion chaperone proteins in Erwinia amylovora. Front. Microbiol. 9:146.

Coutinho, T. A., and Venter, S. N. 2009. Pantoea ananatis: An unconventional plant pathogen. Mol. Plant Pathol. 10:325-335. 
Cui, Z., Jin, G., Li, B., Kakar, K. U., Ojaghian, M. R., Wang, Y., Xie, G., and Sun, G. 2015. Gene expression of type VI secretion system associated with environmental survival in Acidovorax avenae subsp. avenae by principle component analysis. Int. J. Mol. Sci. 16:22008-22026.

Cui, Z., Yang, C. H., Kharadi, R. R., Yuan, X., Sundin, G. W., Triplett, L. R., Wang, J., and Zeng, Q. 2019. Cell-length heterogeneity: A population-level solution to growth/virulence trade-offs in the plant pathogen Dickeya dadantii. PLoS Pathog. 15:e1007703.

Cui, Z., Yuan, X., Yang, C. H., Huntley, R. B., Sun, W., Wang, J., Sundin, G. W., and Zeng, Q. 2018. Development of a method to monitor gene expression in single bacterial cells during the interaction with plants and use to study the expression of the type III secretion system in single cells of Dickeya dadantii in potato. Front. Microbiol. 9:1429.

Datsenko, K. A., and Wanner, B. L. 2000. One-step inactivation of chromosomal genes in Escherichia coli $\mathrm{K}-12$ using PCR products. Proc. Natl. Acad. Sci. U.S.A. 97:6640-6645.

Edmunds, A. C., Castiblanco, L. F., Sundin, G. W., and Waters, C. M. 2013. Cyclic Di-GMP modulates the disease progression of Erwinia amylovora. J. Bacteriol. 195:2155-2165.

Gent, D. H., Lang, J. M., and Schwartz, H. F. 2005. Epiphytic survival of Xanthomonas axonopodis pv. allii and X. axonopodis pv. phaseoli on leguminous hosts and onion. Plant Dis. 89:558-564.

Haapalainen, M., van Gestel, K., Pirhonen, M., and Taira, S. 2009. Soluble plant cell signals induce the expression of the type III secretion system of Pseudomonas syringae and upregulate the production of pilus protein HrpA. Mol. Plant-Microbe Interact. 22:282-290.

Johnson, C. 1940. The maintenance of high atmospheric humidities for entomological work with glycerol-water mixtures. Ann. Appl. Biol. 27:295-299.

Johnson, K. B., Sawyer, T. L., Stockwell, V. O., and Temple, T. N. 2009. Implications of pathogenesis by Erwinia amylovora on rosaceous stigmas to biological control of fire blight. Phytopathology 99:128-138.

Kharadi, R. R., Schachterle, J. K., Yuan, X., Castiblanco, L. F., Peng, J., Slack, S. M., Zeng, Q., and Sundin, G. W. Genetic dissection of the Erwinia amylovora disease cycle. Annu. Rev. Phytopathol. In press.

Kharadi, R. R., and Sundin, G. W. 2020. Cyclic-di-GMP regulates autoaggregation through the putative peptidoglycan hydrolase, EagA, and regulates transcription of the znuABC zinc uptake gene cluster in Erwinia amylovora. Front. Microbiol. 11:605265.

Lee, J. H., Ancona, V., and Zhao, Y. 2018. Lon protease modulates virulence traits in Erwinia amylovora by direct monitoring of major regulators and indirectly through the Rcs and Gac-Csr regulatory systems. Mol. Plant Pathol. 19:827-840.

Li, W., Ancona, V., and Zhao, Y. 2014. Co-regulation of polysaccharide production, motility, and expression of type III secretion genes by EnvZ/OmpR and GrrS/GrrA systems in Erwinia amylovora. Mol. Genet. Genomics 289:63-75.

McNally, R. R., Toth, I. K., Cock, P. J., Pritchard, L., Hedley, P. E., Morris, J. A., Zhao, Y., and Sundin, G. W. 2012. Genetic characterization of the HrpL regulon of the fire blight pathogen Erwinia amylovora reveals novel virulence factors. Mol. Plant Pathol. 13:160-173.

Norelli, J., and Brandl, M. 2004. Survival and growth of Erwinia amylovora on apple leaves. Pages 127-130 in: X Int. Workshop Fire Blight.

Norelli, J. L., Jones, A. L., and Aldwinckle, H. S. 2003. Fire blight management in the twenty-first century: Using new technologies that enhance host resistance in apple. Plant Dis. 87:756-765.

Notti, R. Q., and Stebbins, C. E. 2016. The structure and function of type III secretion systems. Pages 241-264 in: Virulence Mechanisms of Bacterial Pathogens, 5th ed. I. T. Kudva, N. A. Cornick, P. J. Plummer, Q. Zhang, T. L. Nicholson, J. P. Bannantine, and B. H. Bellaire, eds. American Society for Microbiology, Washington, DC, U.S.A.

Oh, C.-S., Kim, J. F., and Beer, S. V. 2005. The Hrp pathogenicity island of Erwinia amylovora and identification of three novel genes required for systemic infection. Mol. Plant Pathol. 6:125-138.

Pester, D., Milčevičová, R., Schaffer, J., Wilhelm, E., and Blümel, S. 2012. Erwinia amylovora expresses fast and simultaneously hrp/dsp virulence genes during flower infection on apple trees. PLoS One 7:e32583.

Pfeilmeier, S., Caly, D. L., and Malone, J. G. 2016. Bacterial pathogenesis of plants: Future challenges from a microbial perspective. Mol. Plant Pathol. 17:1298-1313.

Pusey, P. L. 1997. Crab apple blossoms as a model for research on biological control of fire blight. Phytopathology 87:1096-1102.

Pusey, P. L. 2000. The role of water in epiphytic colonization and infection of pomaceous flowers by Erwinia amylovora. Phytopathology 90: 1352-1357.
Pusey, P. L., and Curry, E. A. 2004. Temperature and pomaceous flower age related to colonization by Erwinia amylovora and antagonists. Phytopathology 94:901-911.

Pusey, P. L., Rudell, D. R., Curry, E. A., and Mattheis, J. P. 2008. Characterization of stigma exudates in aqueous extracts from apple and pear flowers. HortScience 43:1471-1478.

Rufián, J. S., Sánchez-Romero, M. A., López-Márquez, D., Macho, A. P., Mansfield, J. W., Arnold, D. L., Ruiz-Albert, J., Casadesús, J., and Beuzón, C. R. 2016. Pseudomonas syringae differentiates into phenotypically distinct subpopulations during colonization of a plant host. Environ. Microbiol. 18:3593-3605.

Schachterle, J. K., Zeng, Q., and Sundin, G. W. 2019. Three Hfq-dependent small RNAs regulate flagellar motility in the fire blight pathogen Erwinia amylovora. Mol. Microbiol. 111:1476-1492.

Schneider, C. A., Rasband, W. S., and Eliceiri, K. W. 2012. NIH Image to ImageJ: 25 Years of image analysis. Nat. Methods 9:671-675.

Sebaihia, M., Bocsanczy, A. M., Biehl, B. S., Quail, M. A., Perna, N. T., Glasner, J. D., DeClerck, G. A., Cartinhour, S., Schneider, D. J., Bentley, S. D., Parkhill, J., and Beer, S. V. 2010. Complete genome sequence of the plant pathogen Erwinia amylovora strain ATCC 49946. J. Bacteriol. 192:2020-2021.

Spinelli, F., Ciampolini, F., Cresti, M., Geider, K., and Costa, G. 2005 Influence of stigmatic morphology on flower colonization by Erwinia amylovora and Pantoea agglomerans. Eur. J. Plant Pathol. 113:395-405.

Stauber, J. L., Loginicheva, E., and Schechter, L. M. 2012. Carbon source and cell density-dependent regulation of type III secretion system gene expression in Pseudomonas syringae pathovar tomato DC3000. Res. Microbiol. 163:531-539.

Sturm, A., Heinemann, M., Arnoldini, M., Benecke, A., Ackermann, M., Benz, M., Dormann, J., and Hardt, W.-D. 2011. The cost of virulence: Retarded growth of Salmonella Typhimurium cells expressing type III secretion system 1. PLoS Pathog. 7:e1002143.

Thomson, S. V. 1986. The role of the stigma in fire blight infections. Phytopathology 76:476-482.

Triplett, L. R., Melotto, M., and Sundin, G. W. 2009. Functional analysis of the $\mathrm{N}$ terminus of the Erwinia amylovora secreted effector DspA/E reveals features required for secretion, translocation, and binding to the chaperone DspB/F. Mol. Plant-Microbe Interact. 22:1282-1292.

Wei, Z. M., Sneath, B. J., and Beer, S. V. 1992. Expression of Erwinia amylovora hrp genes in response to environmental stimuli. J. Bacteriol. 174:1875-1882.

Wilson, M., Epton, H. A. S., and Sigee, D. C. 1989. Erwinia amylovora infection of hawthorn blossom: II. The stigma. J. Phytopathol. 127: 15-28.

Wilson, M., Hirano, S. S., and Lindow, S. E. 1999. Location and survival of leaf-associated bacteria in relation to pathogenicity and potential for growth within the leaf. Appl. Environ. Microbiol. 65:1435-1443.

Xin, X.-F., Nomura, K., Aung, K., Velásquez, A. C., Yao, J., Boutrot, F., Chang, J. H., Zipfel, C., and He, S. Y. 2016. Bacteria establish an aqueous living space in plants crucial for virulence. Nature 539:524-529.

Yang, S., Peng, Q., San Francisco, M., Wang, Y., Zeng, Q., and Yang, C.-H. 2008. Type III secretion system genes of Dickeya dadantii 3937 are induced by plant phenolic acids. PLoS One 3:e2973.

Yang, S., Zhang, Q., Guo, J., Charkowski, A. O., Glick, B. R., Ibekwe, A. M., Cooksey, D. A., and Yang, C.-H. 2007. Global effect of indole-3-acetic acid biosynthesis on multiple virulence factors of Erwinia chrysanthemi 3937. Appl. Environ. Microbiol. 73:1079-1088.

Yu, X., Lund, S. P., Scott, R. A., Greenwald, J. W., Records, A. H., Nettleton, D., Lindow, S. E., Gross, D. C., and Beattie, G. A. 2013. Transcriptional responses of Pseudomonas syringae to growth in epiphytic versus apoplastic leaf sites. Proc. Natl. Acad. Sci. U.S.A. 110: E425-E434.

Yuan, X., Hulin, M. T., and Sundin, G. W. 2020. Effectors, chaperones, and harpins of the Type III secretion system in the fire blight pathogen Erwinia amylovora: A review. J. Plant Pathol. 103:25-39.

Zeng, Q., McNally, R. R., and Sundin, G. W. 2013. Global small RNA chaperone Hfq and regulatory small RNAs are important virulence regulators in Erwinia amylovora. J. Bacteriol. 195:1706-1717.

Zeng, Q., and Sundin, G. W. 2014. Genome-wide identification of Hfqregulated small RNAs in the fire blight pathogen Erwinia amylovora discovered small RNAs with virulence regulatory function. BMC Genomics 15:414.

Zhao, Y., Sundin, G. W., and Wang, D. 2009. Construction and analysis of pathogenicity island deletion mutants of Erwinia amylovora. Can. J. Microbiol. 55:457-464. 